\title{
Iron status of Asian children aged 2 years living in England
}

\author{
M S Lawson, M Thomas, A Hardiman
}

\begin{abstract}
Haemoglobin and ferritin values were analysed in blood from 1057 children, aged 2 years, of Asian parents living in England. Children who had thalassaemia trait or a current/recent infection were excluded. Twenty nine per cent of Pakistani, $25 \%$ of Bangladeshi, and $20 \%$ of Indian children had haemoglobin $<110.0 \mathrm{~g} / 1$. The recent national diet and nutrition survey of preschool children found a prevalence of $12 \%$ of 2 year olds with haemoglobin < $110.0 \mathrm{~g} / 1$. No single factor accounted for more than a small proportion of the variance in haemoglobin and ferritin values, but the most significant factors that had a negative effect on iron status included the amount of cows' milk consumed, the use of a baby bottle, and mother's place of birth being outside of the UK. Taking vitamin or iron supplements was positively associated with iron status in one or more of the three groups.

(Arch Dis Child 1998;78:420-426)
\end{abstract}

Keywords: ethnic origin; Asian children; iron status; ferritin

In the recent national diet and nutrition survey (NDNS) of children aged 1.5 to 4.5 years, iron deficiency anaemia was identified as a common problem. ${ }^{1}$ About one in eight children aged between 18 and 30 months who provided a blood sample in the NDNS had haemoglobin concentrations below $110.0 \mathrm{~g} / \mathrm{l}$, which is the definition of anaemia suggested by the WHO. ${ }^{2}$ A number of smaller local studies in the UK have shown a much greater proportion of low haemoglobin concentrations among young Asian children with up to half of the children in some studies found to be iron deficient. $^{3}$

This survey provides national data for the

Institute of Child

Health, London, UK

M S Lawson

A Hardiman

Office for National Statistics, London, UK M Thomas

Correspondence to: Ms M Lawson, Childhood Nutrition Research Centre, Institute of Child Health, 30 Guildford Street, London WC1N $1 \mathrm{EH}, \mathrm{UK}$

Accepted 24 December 1997 first time on the iron status of young Asian children. The sample for this study was a group of Asian children living in England who took part in a survey of infant feeding in Asian families when they were about 15 months old, ${ }^{4}$ and were followed up when they were about 2 years old. The survey, which was designed to study the early feeding practices and growth of babies born to mothers of Bangladeshi, Indian, or Pakistani origin, was commissioned by the Department of Health and undertaken by the Social Survey Division of the Office for National Statistics.

\section{Methods}

SAMPLE DESIGN AND RESPONSE

Full details of recruitment and the characteristics of the sample are published elsewhere. ${ }^{4}$ The sample was drawn from the register of births in 41 local authority areas. These areas covered $95 \%$ of the Asian population at the time of the 1991 census. We included all babies born in the relevant local authorities between 15 August and 11 November 1994 to mothers who defined themselves as being of Bangladeshi, Indian, or Pakistani origin. We also included a small sample of babies born to white mothers living in the same geographical areas as the Asian mothers but they were not followed up for this stage of the survey. Mothers were interviewed on four occasions: when the baby was between 6 and 10 weeks old, at 5 months, 9 months, and 15 months. At each stage, anthropometric measurements of the baby were taken. Interviews were achieved when the children were about 15 months old with $71 \%$ (2382) of mothers of babies who were originally eligible.

The 1750 children that we followed up for the current study are the Asian children who participated in the survey at 15 months and whose mothers agreed to be interviewed again. Fieldwork was done during October and November 1996. Two thirds of parents or guardians consented to a blood sample being taken from their child. Ethical approval for the study was given by all 43 NHS local research ethics committees covering the 41 local authority areas in the sample and by the research ethics committee of the Great Ormond Street Hospital for Children NHS Trust.

A total of $1280(73.1 \%)$ mothers of eligible children were successfully contacted when their child was about 2 years old and agreed to at least one interview, which updated information already collected in the infant feeding survey and asked specifically about the consumption of foods which are thought to influence iron status.

Phlebotomists obtained venous blood samples from the antecubital fossa of 1057 (60.4\%) eligible children. They attempted to collect $4.0 \mathrm{ml}$ blood and 799 samples were sufficiently large to include a clotted blood sample to analyse ferritin concentrations. The phlebotomists visited the child's home accompanied by a trained interviewer from the Office for National Statistics and an interpreter where appropriate. Overall, about a third of interviews were done through an interpreter, ranging from $15 \%$ with Indian mothers, $32 \%$ with Pakistani mothers, and $64 \%$ with Bangladeshi mothers. All documents used in the survey were written in English and Asian languages. 
Table 1 Milk drinking habits at 2 years old by ethnic group

\begin{tabular}{llll}
\hline & Bangladeshi & Pakistani & Indian \\
\hline Given milk in a bottle or cup & $92 \%$ & $97 \%$ & $97 \%$ \\
Bottle fed & $85 \%$ & $89 \%$ & $79 \%$ \\
Weighted base $=100 \%$ (all children) & 316 & 418 & 550 \\
Mean (SD) bottles of milk daily & $2.6(1.0)$ & $2.8(1.3)$ & $2.8(1.3)$ \\
Mean (SD) quantity (ml) of milk daily & $487(236)$ & $615(313)$ & $607(315)$ \\
Weighted base = $100 \%$ (bottle fed children) & 270 & 369 & 432 \\
Mean (SD) cups of milk daily & $1.2(1.2)$ & $1.5(1.0)$ & $1.4(1.2)$ \\
Weighted base = $100 \%$ (children given milk in a cup) & 123 & 197 & 353 \\
\hline
\end{tabular}

Pakistani mothers who did not agree to blood being taken from their child were more likely to be better educated. In all groups the proportion of children who were ever breast fed, given vitamins and different types of food and drink at previous stages of the survey was similar among those who gave a blood sample at age 2 and those who did not.

\section{BLOOD ANALYSIS}

Children who were found to have $\beta$ thalassaemia trait $(0.3-2.7 \%)$ or haemoglobin $\mathrm{E}$ trait $(0-7 \%)$ were excluded from the haemoglobin and red cell analyses. Full blood counts were done on the day of receipt of the sample using a Bayer $\mathrm{H} 3$ analyser; serum ferritin assays were done on the Abbott IMX analyser. External quality assessment was by the National External Quality Assessment Scheme, which runs monthly.

Table 2 How often children are given different types of drinks at 2 years old by ethnic group

\begin{tabular}{lccc}
\hline Frequency & Bangladeshi (\%) & Pakistani (\%) & Indian (\%) \\
\hline Other milk drinks & & & \\
$\quad$ At least once a day & 9 & 9 & 10 \\
At least once a week & 14 & 8 & 13 \\
$\quad$ Less than once a week & 4 & 63 & 66 \\
$\quad$ Never & 74 & 57 & 55 \\
Pure fruit juice & 46 & 28 & 26 \\
At least once a day & 30 & 3 & 7 \\
At least once a week & 4 & 11 & 12 \\
Less than once a week & 19 & 52 & 44 \\
Never & 41 & 17 & 6 \\
Ribena, baby, or toddler drinks & 24 & 2 & 32 \\
At least once a day & 2 & 29 & 550 \\
At least once a week & 32 & 418 & \\
Less than once a week & 316 & & \\
$\quad$ Never & & & \\
Weighted base = 100\% & & & \\
\hline
\end{tabular}

${ }^{\star}$ Not in table 1 .

Table 3 How often children are given different types of food at 2 years old by ethnic group

\begin{tabular}{lccc}
\hline Frequency & Bangladeshi (\%) & Pakistani (\%) & Indian (\%) \\
\hline Breakfast cereal & & & 72 \\
At least once a day & 62 & 67 & 16 \\
At least once a week & 25 & 1 & 2 \\
Less than once a week & 1 & 10 & 9 \\
Never & 12 & & \\
Bread, chapati, or naan & & 93 & 81 \\
At least once a day & 46 & 5 & 0 \\
At least once a week & 39 & 0 & 1 \\
Less than once a week & 3 & 1 & 5 \\
Never & 12 & 8 & 4 \\
Chicken, turkey, or other meat & 31 & 88 & 28 \\
At least once a day & 66 & 1 & 2 \\
At least once a week & 1 & 3 & 51 \\
Less than once a week & 2 & 1 & 12 \\
Never & & 75 & 36 \\
Fish & 22 & 12 & 550 \\
At least once a day & 58 & 12 & \\
At least once a week & 6 & 418 & \\
Less than once a week & 14 & & \\
Never & 316 & & \\
Weighted base = 100\% & & & \\
\hline
\end{tabular}

\section{Results}

We considered results separately for each of the three ethnic groups because, as described in the report of the survey, the characteristics of the groups were quite different from each other. ${ }^{4}$

DIETARY AND LIFESTYLE QUESTIONNAIRE

Tables 1-3 present data obtained at the two year interview. Socioeconomic factors and data on feeding practices, diet, and growth have been brought forward from the previous stages of the infant feeding survey and used in the analysis described in this paper. The full results of the first four interviews are published in the report of that survey. ${ }^{4}$

Table 1 shows the milk drinking habits of the group at 2 years of age: $97 \%$ of Indian and Pakistani children and $92 \%$ of Bangladeshi children were given milk; $89 \%$ of Pakistani, $85 \%$ of Bangladeshi, and $79 \%$ of Indian children still drank milk from a bottle, even if only occasionally. Most children who were given milk in a bottle or a cup received whole milk, but $8 \%$ of Indian and Bangladeshi and $7 \%$ of Pakistani children were given semiskimmed milk (compared with $14 \%$ in the NDNS). One per cent or less in any group were given skimmed milk. Table 2 shows consumption of other drinks such as juices.

Table 3 shows how often children ate selected foods. Seventy two per cent of Indian children, $67 \%$ of Pakistani, and $62 \%$ of Bangladeshi children ate breakfast cereals daily. More than $90 \%$ of Indian and Pakistani children ate bread, naan, or chapati daily. Bangladeshi children ate them less frequently: $46 \%$ at least once a day, but $85 \%$ at least once a week. Twenty eight per cent of Indian children never ate meat. Bangladeshi children were the most likely $(31 \%)$ to eat meat every day. Although Pakistani children did not eat meat as frequently as this, $96 \%$ ate meat at least once a week. Twenty two per cent of Bangladeshi children ate fish at least once a day. Only $1 \%$ of Pakistani and $2 \%$ of Indian children ate fish that frequently, but $75 \%$ of Pakistani and about $50 \%$ of the Indian children ate fish at least once a week. Thirty six per cent of Indian, $14 \%$ of Bangladeshi, and $12 \%$ of Pakistani children never ate fish.

At age 2 years, $46 \%$ of Indian, $43 \%$ of Bangladeshi, and $38 \%$ of Pakistani children were given vitamin or iron supplements. Three per cent of Pakistani and $2 \%$ of Indian and Bangladeshi children were given iron supplements. About a quarter of children in all groups were given Department of Health vitamin drops containing vitamins $\mathrm{A}, \mathrm{D}$, and $\mathrm{C}$. 
Table 4 Haemoglobin concentration by ethnic group excluding children with $\beta$ thalasssaemia or HbE trait

\begin{tabular}{lcccc}
\hline $\begin{array}{l}\text { Haemoglobin } \\
\text { concentraton }(g / l)\end{array}$ & Bangladeshi (\%) & Pakistani (\%) & Indian (\%) & $\begin{array}{l}\text { NDNS } \\
1.5-2.5 \text { years }\end{array}$ \\
\hline$<100.0$ & 13 & 14 & 9 & 2 \\
$<105.0$ & 16 & 19 & 13 & 4 \\
$<110.0$ & 25 & 29 & 20 & 12 \\
$<120.0$ & 58 & 59 & 58 & 51 \\
$<130.0$ & 87 & 91 & 91 & 84 \\
$<140.0$ & 98 & 99 & 99 & 99 \\
All & 100 & 100 & 100 & 100 \\
Weighted base & 239 & 311 & 430 & 310 \\
Mean & 116 & 114 & 116 & 120 \\
Median & 118 & 117 & 118 & 119 \\
Lower 2.5 centile & 84 & 80 & 90 & 102 \\
Upper 2.5 centile & 140 & 137 & 136 & 137 \\
SE & 0.9 & 0.8 & 0.5 & 0.5 \\
SD & 14.5 & 14.1 & 10.9 & 9.2 \\
\hline
\end{tabular}

NDNS, National Diet and Nutrition Survey: children aged $1.5-4.5$ years. ${ }^{1}$ Data for children aged $1.5-2.5$ years.

Table 5 Serum ferritin concentration by ethnic group

\begin{tabular}{|c|c|c|c|c|}
\hline Serum ferritin $(\mu g / l)$ & Bangladeshi (\%) & Pakistani (\%) & Indian (\%) & $\begin{array}{l}\text { NDNS } \\
1.5-2.5 \text { years }\end{array}$ \\
\hline$<5.0$ & 8 & 13 & 7 & 9 \\
\hline$<10.0$ & 39 & 45 & 41 & 28 \\
\hline$<20.0$ & 74 & 75 & 76 & 60 \\
\hline$<30.0$ & 92 & 90 & 89 & 77 \\
\hline Weighted base & 197 & 252 & 350 & 300 \\
\hline Mean (average value) & 15.0 & 13.9 & 15.7 & 21.0 \\
\hline Median & 11.0 & 10.0 & 12.0 & 16.0 \\
\hline Lower 2.5 centile & 3.0 & 3.0 & 3.0 & 4.0 \\
\hline Upper 2.5 centile & 49.2 & 42.3 & 57.7 & 78.0 \\
\hline SE & 0.82 & 0.69 & 0.76 & 1.10 \\
\hline SD & 11.48 & 10.98 & 14.20 & 18.70 \\
\hline
\end{tabular}

NDNS, National Diet and Nutrition Survey: children aged $1.5-4.5$ years. ${ }^{1}$ Data for children aged $1.5-2.5$ years.

Table 6 Factors found by bivariate analysis to be related to haemoglobin $<110.0 \mathrm{~g} / \mathrm{l}$

\begin{tabular}{|c|c|c|c|}
\hline & Bangladeshi & Pakistani & Indian \\
\hline Bottle fed from birth & NS & Yes & NS \\
\hline Bottle fed-mainly casein formula at 5 months & NS & NS & Yes \\
\hline Bottle fed-mainly cows' milk at 9 months & Yes & Yes & NS \\
\hline Milk in bottle or cup-mainly cows' milk at 15 months & NS & NS & Yes \\
\hline Bottle fed at age $2-600 \mathrm{ml}$ or more of cows' milk daily & NS & Yes & NS \\
\hline Bottle fed at age $2-700 \mathrm{ml}$ or more of cows' milk daily & NS & NS & Yes \\
\hline \multicolumn{4}{|l|}{ Among those with the fastest rate of growth from birth to } \\
\hline 15 months & Yes & NS & NS \\
\hline Second or later baby & NS & Yes & NS \\
\hline
\end{tabular}

Yes, significant at the $95 \%$ confidence interval.

\section{BLOOD RESULTS}

The mean haemoglobin values for Bangladeshi and Indian children was $116.0 \mathrm{~g} / 1$ and for Pakistani children $114.0 \mathrm{~g} / \mathrm{l}$, compared with a mean of $120.0 \mathrm{~g} / 1$ for children aged 1.5 to 2.5 in the NDNS. Twenty nine per cent of Pakistani children, $25 \%$ of Bangladeshi, and $20 \%$ of Indian children had haemoglobin concentrations below $110.0 \mathrm{~g} / 1$ compared with the NDNS results of $12 \%$ below $110.0 \mathrm{~g} / 1$ (table 4 ).

Table 7 Factors found by bivariate analysis to be related to ferritin $<10.0 \mu \mathrm{g} / \mathrm{l}$

\begin{tabular}{llll}
\hline & Bangladeshi & Pakistani & Indian \\
\hline Bottle fed-mainly casein formula at 5 months & Yes & NS & NS \\
Bottle fed-mainly cows' milk at 9 months & Yes & Yes & NS \\
Milk in bottle or cup-mainly cows' milk at 15 months & NS & NS & Yes \\
Bottle fed at age 2-500 ml or more of cows' milk daily & Yes & NS & NS \\
Bottle fed at age 2-700 ml or more of cows' milk daily & NS & Yes & Yes \\
Does not eat meat daily & Yes & NS & NS \\
Among those with the fastest rate of growth to 15 months & Yes & NS & NS \\
Not given vitamins at age 2 & NS & NS & Yes \\
Second or later baby & NS & NS & Yes \\
Number of children in the family & NS & Yes & NS \\
Mother not born in UK & NS & Yes & NS \\
Mother has little or no understanding of English & NS & Yes & NS \\
\hline
\end{tabular}

Yes, significant at the $95 \%$ confidence interval.
The mean ferritin concentrations were $15.7 \mu \mathrm{g} / \mathrm{l}$ for Indian, $15.0 \mu \mathrm{g} / \mathrm{l}$ for Bangladeshi, and $13.9 \mu \mathrm{g} / 1$ for Pakistani children. The mean concentrations for children in the NDNS was $21.0 \mu \mathrm{g} / \mathrm{l}$. If the lower limit of the normal range is taken as $10.0 \mu \mathrm{g} / 1,{ }^{5}$ then $45 \%$ of Pakistani, $41 \%$ of Indian, and $39 \%$ of Bangladeshi children had values below this compared with $28 \%$ of children from the NDNS (table 5).

FACTORS AFFECTING HAEMOGLOBIN AND

FERRITIN CONCENTRATIONS

Table 6 shows the characteristics of children with a haemoglobin concentration $<110.0 \mathrm{~g} / 1$ and table 7 shows the characteristics of children with a ferritin concentration $<10 \mu \mathrm{g} / \mathrm{l}$, which proved to be significant in bivariate analysis. Some of these factors may be interrelated. By using a modelling analysis (multiple regression) it is possible to identify the factors that have the greatest impact on, for example, the child's haemoglobin concentration and those that have no significant impact when the main factors have been taken into account. The variables included in the analysis are those that might be expected from the bivariate analysis of data from this study or from previous studies (see discussion) to have a significant effect on the concentration of haemoglobin or ferritin. The distribution of ferritin was skewed so a log transformation was done.

Table 8 shows variables significant for at least one ethnic group in predicting haemoglobin and ferritin concentrations. Table 9 shows characteristics associated with haemoglobin concentration at age 2 years, and table 10 shows characteristics associated with ferritin concentration at this age. As only two thirds of the samples collected were sufficiently large to include a ferritin estimation, the model to analyse the characteristics associated with ferritin are based on a smaller sample than that described for haemoglobin.

The two most significant factors affecting haemoglobin concentrations of Bangladeshi and Pakistani children were a negative association between haemoglobin at age 2 and weight gain from birth to 15 months and whether they were mainly given cows' milk at 9 months. The haemoglobin values of Pakistani children were also negatively related to the number of children in the family. Among Bangladeshi children, the amount of cows' milk consumed in a bottle at 2 years of age was also a significant factor. Bivariate analysis showed that Bangladeshi children who were anaemic were significantly more likely to be bottle fed and consumed on average $600 \mathrm{ml}$ or more of cows' milk daily.

The significant factors affecting haemoglobin concentrations of Indian children differed from other groups. They were more likely to have a lower haemoglobin concentration if they were mainly given cows' milk at 15 months or their mother was Muslim. Indian children were likely to have higher haemoglobin concentrations if they received a vitamin supplement or ate cereal at 2 years of age.

Among children in all groups, the two most significant factors that affected the concentra- 
Table 8 Variables included in multiple regression to predict haemoglobin and ferritin concentrations

\begin{tabular}{llc}
\hline & Haemoglobin & Ferritin \\
\hline Variables significant for at least one ethnic group & & \\
Fed cows' milk at 9 months & Yes & Yes \\
Fed cows' milk at 15 months & Yes & Yes \\
Amount of cows' milk drunk at 2 years & Yes & Yes \\
Weight gain-birth to 15 months & Yes & Yes \\
Whether given vitamins at 2 years & Yes & Yes \\
Whether eats cereal daily & Yes & NS \\
Number of siblings & Yes & NS \\
Mother's country of birth & NS & Yes \\
Mother's religion-Muslim & Yes & NS
\end{tabular}

Variables not significant for any group

Bottle fed from birth

Fed casein formula at 9 weeks

Fed casein formula at 5 months

Age first ate solid food

Whether family received income support

Mother's understanding of English

Whether ate meat or fish daily at 2 years

Whether weaning problems reported at 15 months

Birth weight

Birth order

Yes, significant at the $95 \%$ confidence interval.

tion of ferritin at 2 years old were whether they were mainly given cows' milk at 15 months and the amount of cows' milk consumed in a bottle at 2 years of age. Pakistani children were also likely to have a lower concentration of ferritin if they were mainly given cows' milk at 9 months.

Although the models indicate factors that affect haemoglobin and ferritin values, a large proportion of the variance is still unexplained. The proportion of the variance explained by the models to predict haemoglobin was $9-10 \%$ and those to predict ferritin levels was $11-17 \%$. While these figures are not unusual for this type of modelling, the results should be used with care.

\section{Discussion}

IRON DEFICIENCY IN ETHNIC GROUPS

This is the first large, nationally representative survey of Asian children covering most areas with an Asian community in England. The

Table 9 Characteristics associated with haemoglobin concentration at 2 years old

\begin{tabular}{llll}
\hline & Bangladeshi & Pakistani & Indian \\
\hline All childrent & & & \\
Constant: base haemoglobin (g/1) & 135.8 & 130.8 & 118.0 \\
Weight gain: birth to 15 months & $-2.14^{\star \star}$ & $-1.62^{\star \star}$ & NS \\
Cows' milk at 9 months & $-6.11^{\star \star}$ & $-7.30^{\star \star}$ & NS \\
Amount of cows' milk at 2 years & $-0.008^{\star}$ & NS & NS \\
Number of siblings & NS & $-1.40^{\star}$ & NS \\
Given vitamins at 2 years & NS & NS & $4.00^{\star \star}$ \\
Cows' milk at 15 months & NS & NS & $-5.31^{\star \star}$ \\
Eats cereal daily & NS & NS & $2.43^{\star}$ \\
Muslim & NS & NS & $-2.83^{\star}$ \\
Percentage of variance explained by model & 10 & 9 & 9 \\
\hline
\end{tabular}

${ }^{\star} \mathrm{p}<0.05 ;{ }^{\star \star} \mathrm{p}<0.01$.

†Children with $\beta$ thalassaemia or haemoglobin E trait excluded.

Table 10 Characteristics associated with concentration of ferritin (log values) at 2 years old

\begin{tabular}{llll}
\hline & Bangladeshi & Pakistani & Indian \\
\hline Constant: base ferritin $(\mu \mathrm{g} / \mathrm{l})$ & 3.96 & 3.78 & 2.93 \\
Cows' milk at 15 months & $-0.42^{\star \star}$ & $-0.37^{\star \star}$ & $-0.46^{\star \star}$ \\
Amount of cows' milk at 2 years & $-0.0005^{\star \star}$ & $-0.0004^{\star \star}$ & $-0.0003^{\star \star}$ \\
Weight gain: birth to 15 months & $-0.13^{\star \star}$ & $-0.08^{\star}$ & $\mathrm{NS}$ \\
Mother not born in UK & $\mathrm{NS}$ & $-0.25^{\star}$ & $\mathrm{NS}$ \\
Cows' milk at 9 months & $\mathrm{NS}$ & $-0.38^{\star \star}$ & $\mathrm{NS}$ \\
Given vitamins at 2 years & $\mathrm{NS}$ & $\mathrm{NS}$ & $0.21^{\star \star}$ \\
Percentage of variance explained by model & 16 & 17 & 11 \\
\hline
\end{tabular}

${ }^{\star} \mathrm{p}<0.05 ;{ }^{\star \star} \mathrm{p}<0.01$ prevalence of anaemia (20-29\%) concords with the local smaller studies done in the past 10 years, which have described a high prevalence of anaemia (defined as haemoglobin $<110.0 \mathrm{~g} / \mathrm{l}$ ) in young Asian children compared with white children living in the same areas: Ehrhardt surveyed children aged between 6 months and 4 years admitted to hospital in Bradford and found a prevalence of $28 \%$ with a low haemoglobin concentration in 225 Asian children (mainly Pakistani) compared with $12 \%$ in 373 non-Asian children ${ }^{6} ; 68 \%$ of a sample of 55 Asian 2 year olds had a haemoglobin $<120.0 \mathrm{~g} / 1$ in a study in Rochdale compared with $23 \%$ of a similar sample size of white children of the same age ${ }^{7}$; a study of 511 year old infants in London found a prevalence of $26 \%$ in Asian children (mainly Bangladeshi) and $12 \%$ in non-Asians ${ }^{8}$; a later study also in east London screened children aged 8 months to 2 years and found a prevalence of anaemia of $16 \%$ in Asian (mainly Pakistani) and $9 \%$ in white children (sample size 62 and 52 respectively) $)^{9}$; Marder et al found a prevalence of $39 \%$ anaemia in 44 Asian children from inner city Nottingham aged 15 months to 2 years and $16 \%$ in white children. ${ }^{10}$ A number of studies that did not include a white comparison group have described a high prevalence of haemoglobin < $110.0 \mathrm{~g} / \mathrm{l}$ : Grindulis et al studied 135 Asian children aged 22 months in Birmingham and described a prevalence of $31 \%$ anaemia ${ }^{11}$; a prevalence of $24 \%$ was described in 138 Asian children in Sheffield aged 12 months to 2 years. ${ }^{12}$

\section{FERRITIN}

Serum ferritin is reduced in iron deficiency, and in adults correlates with the quantity of storage iron in the body. ${ }^{13}$ It would be expected to decrease before erythropoiesis would be affected, although this did not seem to be the case in these groups, as indicators of iron deficient erythropoiesis were detected in many more children than the $8-13 \%$ who had low ferritin values. Most studies where a high prevalence of haemoglobin $<110.0 \mathrm{~g} / 1$ has been found also describe a high prevalence of ferritin values below $10 \mu \mathrm{g} / \mathrm{l}$ for Asian and white children; in the most recent study, $48 \%$ of children had low ferritin values and $24 \%$ also had low haemoglobin concentrations ${ }^{12}$; other studies in children have described a prevalence of low ferritin values of approximately double the prevalence of low haemoglobin values. ${ }^{6}{ }^{8}$ In the NDNS for children aged 1.5 to 2.5 years a correlation between haemoglobin concentration and ferritin of $0.12(p<0.05)$ was found. Twenty eight per cent of children had low ferritin values compared with $12 \%$ with low haemoglobin values. A significant correlation of 0.37 (Bangladeshi), 0.32 (Pakistani), 0.21 (Indian) $(p<0.01)$ was found between haemoglobin and ferritin in this study, although we find it difficult to explain the unexpectedly high proportion who had normal ferritin concentrations. Infection is known to increase serum ferritin values, and it may be may be that the Asian children in this study had more infections than their white counterparts in the 
NDNS study, although children with a current or recent infection were not asked to give a blood sample. It has been noted in a previous study that Asian parents reported more infections in their children during their first year compared with white children. ${ }^{7}$

DIET

A number of dietary practices that may predispose to iron deficiency have been described in Asian populations in the UK. Compared with white mothers, Asian mothers tend to introduce solid foods later, ${ }^{781415}$ and although we confirmed this finding, ${ }^{4}$ more than $90 \%$ of children from all groups were receiving some solids by 4 months of age. Asian children are reported to receive more sweet desserts and fewer savoury and meat based foods than white children during infancy, ${ }^{75}$ although Thomas and Avery showed that only Bangladeshi children ate desserts more frequently than white children. ${ }^{4}$ In the current study, meat consumption at 2 years of age was not found to be significantly associated with iron status. The Asian children consumed meat less frequently at 15 months than did white children; $53 \%$ of Bangladeshi, $30 \%$ of Pakistani, and $21 \%$ of Indian children ate meat daily compared with $69 \%$ of white children. Twenty two per cent of Indian households were vegetarian.

Apart from milk, the only food that was significantly associated with iron status was seen in Indian children, where those who ate breakfast cereal daily at 2 years of age were less likely to be anaemic. Data on iron content of cereals was not documented, but the majority of breakfast cereals in the UK are fortified with iron.

Although there appears to be no correlation between dietary iron intake and iron status, ${ }^{9}$ iron intake in Asian children has been described as being similar to, ${ }^{7}$ or lower than, ${ }^{9}{ }^{12} 13$ similar samples of white children. Some attempts have been made to make a more general assessment of diet, ${ }^{16}$ and in a mainly white sample of children in Montreal, iron deficiency was associated with a "poor diet". ${ }^{17}$ In our study, white children at 15 months ate a greater variety of foods in their diet than any of the Asian groups. ${ }^{4}$

A characteristic of Asian weaning diets is the emphasis and value put on cows' milk as a staple food for young children. Asian mothers tend to introduce cows' milk as a main drink earlier than white families do and encourage young children to drink larger quantities, with up to $60 \%$ of energy intake at 18 months derived from milk. ${ }^{12}$ Several studies have described an increased risk of poor iron status in children who received cows' milk as their main drink before 1 year of age. Most have found that the introduction of cows' milk at 6 months of age results in a poorer iron status between 1 and 2 years of age compared with children who received an iron fortified formula until the age of $1,^{818}$ and one study showed that continuing with an iron fortified formula until 18 months had an advantage in terms of iron status at age two years. ${ }^{20}$ Two studies have not shown any association between age of introduction of cows' milk and subsequent iron status. ${ }^{112}$ Mills described an effect of cows' milk on iron status after introduction at 8 months of age. ${ }^{9}$ In our study, the introduction of cows' milk at 9 months increased the risk of iron deficiency in Bangladeshi and Pakistani children. The iron status of Indian children was only affected if cows' milk was given at age 15 months. This study endorses the recommendation by the Department of Health that cows' milk should not be used as a main drink before the age of $1 .^{21}$

The quantity of cows' milk was shown to be negatively associated with iron status; Bangladeshi and Pakistani children who consumed more than $600 \mathrm{ml}$ daily and Indian children who consumed more than $700 \mathrm{ml}$ daily were found to be at greater risk of iron deficiency. These quantities are considerably smaller than the volumes associated with poor iron status in some earlier studies. Morton suggested that an intake of $900 \mathrm{ml}$ was a risk factor for iron deficiency, ${ }^{8}$ although Kim found that as little as $500 \mathrm{ml}$ at 6 months had an effect. ${ }^{19}$ Mills found no direct correlation between volume of milk consumed and haemoglobin concentrations but did report that iron deficiency was more common in Asian children consuming more than $1000 \mathrm{ml}$ daily. ${ }^{9}$ The use of feeding bottles after the age of 1 was associated with higher milk consumption, ${ }^{4}$ and previous studies have described prolonged use of feeding bottles in Asian children. ${ }^{71415}$ We found that at 15 months at least $90 \%$ of Asian children were still bottle fed, if only partially, compared with $75 \%$ of white children; $67 \%$ of white children drank milk from a cup at this age compared with 50\% of Indian, $41 \%$ of Pakistani, and $26 \%$ of Bangladeshi children. ${ }^{4}$ The addition of cereal or sugar is more common among Asian mothers ${ }^{14}$; in the current survey approximately a third of Bangladeshi mothers added something to the milk of their 15 month old child: mainly rusk, baby rice, or other cereal; $10 \%$ of Pakistani mothers added sugar. It is likely that sweetening the milk and the use of a baby bottle compared with a cup is likely to encourage a high consumption of milk to the detriment of other foods. Milk is a valuable food for children and $600 \mathrm{ml}$ is commonly recommended as being a suitable volume; further work needs to be done on the optimum quantity of milk for young children.

\section{GROWTH AND IRON STATUS}

Birth weight and growth velocity are considered to be major influences on iron status during 6-12 months of age. Faster growing children are theoretically at greater risk of deficiency; evidence is conflicting, although most studies have considered a younger age group than those in this study. No correlation was found between growth and iron status up to 1 year of age in one study, ${ }^{22}$ while Morton found that iron deficiency at 1 year of age was significantly correlated with a greater weight gain. ${ }^{8}$ Two studies of white children in Europe have described a negative effect of growth velocity on iron stores although not on haemoglobin values. In one study, infants were measured at 
1 year, ${ }^{23}$ whereas the other study examined older children with a mean age of 7.1 years. ${ }^{24}$ In our study, we found no relation between weight gain up to 15 months and haemoglobin values, but ferritin values showed a significant relation with weight gain between birth and 15 months in the Bangladeshi group. We find this difficult to explain because Bangladeshi children were smaller than white children and children from the other Asian groups at 15 months of age, ${ }^{4}$ and although their increases in length and weight from birth to 15 months were larger than for the white group, the increase was still smaller than that seen in the two other Asian groups.

\section{SOCIOECONOMIC AND ETHNIC FACTORS}

We examined socioeconomic factors such as family size, income, education, and birthplace of mother. None of these factors showed an association with iron status for any of the Asian groups. The iron status of Pakistani children was negatively associated with the number of siblings in the family. Among Bangladeshi and Pakistani children, iron status was negatively associated with the mother being born outside of the UK; in addition, Bangladeshi children tended to have poorer iron status if their mother did not have a good understanding of English. Indian children were more likely to have poorer iron status if their mother's religion was Muslim; this may reflect the socioeconomic characteristics of Indian Muslims who, in our study, tended to be less well educated than other Indian mothers.

We have difficulty in explaining the reason for different factors being associated with iron status in the three groups who all originated from the same sub-continent; the higher prevalence of iron deficiency in the Pakistani children is puzzling also because Pakistanis have usually been established in the UK for longer than Bangladeshis, who tend to be among the more recent immigrants. In the current study, $68 \%$ of Bangladeshi, $56 \%$ of Pakistani, and $50 \%$ of Indian mothers had arrived in the UK within the past 10 years. ${ }^{4}$ Differences in red cell indices between AfroCaribbean and white ethnic groups has recently been reported. ${ }^{25}$ Wharton questions the possibility of a genetic influence on the expression of transferrin and transferrin receptors. ${ }^{26}$ The prevalence of iron deficiency is higher for children in Africa and southern Asia than in other areas of the developing world ${ }^{27}$ It may be that there are racial differences, and our data require further analysis to determine whether it is appropriate to compare Asian children directly with white children.

\section{CONCLUSIONS}

There is considerable evidence of an association between iron deficiency and impaired mental and motor function in childhood in various ethnic groups, ${ }^{28}$ although a causative effect of iron deficiency has been questioned. ${ }^{29}$ We are concerned that our large national study has confirmed that up to one third of children from three different Asian groups in the UK have haemoglobin concentrations that may be associated with delayed development. The downward trend in the prevalence of iron deficiency seen in the United States during the 1970 s seems not to have occurred here ${ }^{30}$; it is interesting to note that this trend appears to have reached a plateau with a prevalence of iron deficiency among children aged 1 to 2 years in the United States that is slightly lower (9\%) than the NDNS study. ${ }^{31}$ No single factor or, indeed, no model using a number of factors explains more than a small proportion of the variance in the current study. The causes of low haemoglobin values in this group remain largely unexplained; further work needs to be done to determine appropriate normal values of indicators of iron status in populations of non-white children: whether there are differences in iron absorption in young Asian children and what are the specific effects of poverty and infection on iron status. A number of prevention strategies have been suggested, ${ }^{32}$ but before such strategies can be successful, more evidence is needed about the mechanisms underlying iron deficiency in young children.

We thank Diana Muggleston (haematology department, Great Ormond Street Hospital for Children) and Vivienne Avery (Office for National Statistics) for their contribution to the study. The study was funded by the Department of Health, whose staff also provided support. The study would not have been possible without the help of colleagues in the Social Survey Division of the Office for National Statistics, the interviewers, phlebotomists, and especially the families who participated in the study.

1 Gregory JR, Collins DL, Davies PS, et al. National diet and nutrition survey: children aged 1.5 to 4.5 years. Vol 1 . Report of the diet and nutrition survey. London: HMSO, 1995.

2 WHO. Nutritional anaemias. WHO technical report series no 503. Geneva: WHO, 1972.

3 Lawson M. Iron in infancy and childhood. In: British nutrition foundation. Iron. Nutritional and physiological significance. London: Chapman and Hall, 1995:93-105.

4 Thomas M, Avery V. Infant feeding in Asian families. London: The Stationery Office, 1997.

5 Dallman PR, Looker AC, Johnson CL, et al. Influence of age on laboratory criteria for the diagnosis of iron deficiency on laboratory criteria for the diagnosis of iron deficiency Hallberg L, Asp NG, eds. Iron nutrition in health and disease. Hallberg L, Asp NG, eds. Iron nutrition

6 Erhardt P. Iron deficiency in young Bradford children from 6 Erhardt P. Iron deficiency in young Bradford chil

7 Warrington S, Storey DM. Comparative studies on Asian and Caucasian children 1: growth; 2 : nutrition, feeding practices, and health. Eur F Clin Nutr 1988;42:61-7, 69-80.

8 Morton RE, Nysenbaum A, Price K. Iron status in the first year of life. F Pediatr Gastroenterol Nutr 1988;7:707-12.

9 Mills AF. Surveillance for anaemia: risk factors in patterns of milk intake. Arch Dis Child 1990;65:428-31.

10 Marder E, Nicoll A, Polnay L, et al. Discovering anaemia at child health clinics. Arch Dis Child 1990;65:892-4.

11 Grindulis H, Scott PH, Belton NR, et al. Combined deficiency of iron and vitamin D in Asian toddlers. Arch Dis Child 1986;61:843-8.

12 Duggan MB, Steel G, Elwys G, et al. Iron status, energy intake, and nutritional status of healthy young Asian children. Arch Dis Child 1991;66:1386-9.

13 Worwood M. Mechanisms of cellular iron status. British Nutrition Foundation. Iron. Nutritional and physiological significance. London: Chapman and Hall, 1995:17-22.

14 Williams SA, Sahota P, Fairpo CG. Infant feeding practices within white and Asian communities in inner city Leeds. $\mathcal{F}$ Hum Nutr and Dietet 1989;2:325-38.

15 Williams SA, Sahota P. An enquiry into the attitudes of Muslin Asian mothers regarding infant feeding practices and dental health. F Hum Nutr Dietet 1990;3:393-401.

16 Boutry M, Needham R. Use of diet history in the screening of iron deficiency. Pediatrics 1996;9:1138-41.

17 Lehman F, Gray Donald K, Mongeon M, et al. Iron deficiency anaemia in 1 year old children of disadvantaged families in Montreal. Can Med Assoc $\mathcal{F} 1992 ; 146: 1571-7$.

18 Tunessen WW Jr, Oski FA. Consequences of starting whole cows' milk at 6 months of age. F Paediatr 1987;111:813-16.

19 Kim SK, Cheong WS, Jun YH, et al. Red blood cell indices and iron status according to feeding practices in infants and young children. Acta Paediatr 1996;85:139-44.

20 Daley A, MacDonald A, Aukett A, et al. Prevention of anaemia in inner city toddlers by an iron supplemented cows' milk formula. Arch Dis Child 1996;75:9-16 
21 Department of Health. Weaning and the weaning diet. Report on health and social subjects No 45. London: HMSO, Report
1994.

22 Hasckhe F, Vanura H, Male C, et al. Iron nutrition and growth of breast and formula fed infants during the first 9 months of life. F Pediatr Gastroenterol Nutr 1993;16:151-6.

23 Micaelson KF. Nutrition and growth during infancy. Acta Pediatr 1997;86(suppl):420.

24 Vihervuori E, Cook JD, Siimes MA. Iron status of children with short stature during accelerated growth due to growth hormone treatment. Acta Pediatr 1997;86:588-93.

25 Himes JH, Walker SP, Williams S, et al. A method to estimate the prevalence of iron deficiency in adolescent Jamaican girls. Am 7 Clin Nutr 1977;65:831-6.

26 Wharton BA. Iron nutrition in childhood: the interplay of genes, development and environment. Acta Pediatr Scand 1989;36(suppl):5-11.
27 De-Maeyar E, Adiels Tegman M. The prevalence of anaemia in the world. World Health Stat Q 1985;38:302-16. 28 Walter $T$. Effect of iron deficiency anaemia on cognitive skills in infancy and childhood. In: Hallenberg L, Asp NG, eds. Iron nutrition in health and disease. London: John Libbey, 1996:219-29.

29 Logan S. Commentary on iron deficiency anaemia in infancy and early childhood. Arch Dis Child 1997;76: $553-4$.

30 Yip B, Binkin NJ, Fleshood L, et al. Declining prevalence of naemia among low income children in the United States 1987;258:1619-23.

31 Looker AC, Dallman PR, Carroll MD, et al. Prevalence of ron deficiency in the United States. FAMA 1997;277: 973-6.

32 Booth IW, Aukett MA. Iron deficiency anaemia in infancy and early childhood. Arch Dis Child 1997;76:549-54. 